\title{
Comparing the safety and efficacy of intravenous iron sucrose and intravenous ferric carboxymaltose in treating postpartum anemia
}

\author{
Shakun Singh*, Vandana Dhama, Rachna Chaudhary, Preeti Singh
}

Department of Obstetrics and Gynaecology, LLRM Medical College, Meerut, Uttar Pradesh, India

Received: 23 February 2016

Revised: 24 February 2016

Accepted: 18 March 2016

\section{*Correspondence:}

Dr. Shakun Singh,

E-mail: singhshakun77@gmail.com

Copyright: ( ) the author(s), publisher and licensee Medip Academy. This is an open-access article distributed under the terms of the Creative Commons Attribution Non-Commercial License, which permits unrestricted non-commercial use, distribution, and reproduction in any medium, provided the original work is properly cited.

\section{ABSTRACT}

Background: Anaemia is the most common hematological abnormality diagnosed during pregnancy. As per WHO, anaemia during pregnancy is defined as haemoglobin concentration of less than $11 \mathrm{gm} \%(7.45 \mathrm{mmol} / \mathrm{L})$ and haematocrit less than $33 \%$. The objective of this study was to compare the safety and efficacy of intravenous iron sucrose and i.v. ferric carboxymaltose in treating postpartum anemia.

Methods: This open label, interventional, prospective study was carried out in 200 postpartum patients with Anemia in the department of obstetrics and gynecology, LLRM Medical College, Meerut, Uttar Pradesh, India from November 2014 to November 2015. The subjects were randomized in 1:1 ratio of two groups. First approved receiving $500 \mathrm{mg}$ of intravenous iron sucrose divided in three doses on alternate days (200 mg, $200 \mathrm{mg}$, and $100 \mathrm{mg}$ ). Second receiving $500 \mathrm{mg}$ of intravenous ferric carboxymaltose (Ferium, Emcure Pharmaceuticals).

Results: Maximum number of patients of our study belonged to low socioeconomic group, significantly higher number of women achieved $\mathrm{Hb}>11 \mathrm{gm} / \mathrm{dl}$ in FCM group. 88 women in FCM group achieve $\mathrm{Hb}$ rise of 2 gm as compared to only 24 in iron sucrose group, which was highly significant ( $\mathrm{P}$ value $<0.001$ ) mean size of Hb was 2.086 $\mathrm{mg}$ for FCM group and $1.766 \mathrm{gm}$ for iron sucrose group, which was also significant. Serum ferritin, which is a marker of iron stores rise much higher $67.6 \mathrm{mg} / \mathrm{ml}$ in ferric carboxymaltose group as compared to $47.88 \mathrm{mg} / \mathrm{ml}$ for iron sucrose group.

Conclusions: Ferric carboxymaltose is an efficient alternative to Iron Sucrose in treating postpartum anemia. It has an added advantage of single dose regime and lower incidence of side effects.

Keywords: Iron sucrose, Ferric carboxymaltose, Postpartum anemia

\section{INTRODUCTION}

Anaemia is the most common haematological abnormality diagnosed during pregnancy. As per WHO, anaemia during pregnancy is defined as haemoglobin concentration of less than $11 \mathrm{gm} \%(7.45 \mathrm{mmol} / \mathrm{L})$ and haematocrit less than $33 \%{ }^{1}$

The centre of disease control and prevention (1990) defined anaemia as less than $10 \mathrm{gm} / \mathrm{dl}$ in first and third trimester and less than $10.5 \mathrm{gm} / \mathrm{dl}$ in second trimester. ${ }^{2}$
Whereas ICMR (The Indian Council of Medical Research) categorize, anaemia in four categories, which are;

Table 1- ICMR Classification of anemia.

\begin{tabular}{|lll|}
\hline Category & Anaemia severity & Hb level in gm/dl \\
\hline 1 & Mild & $10-10.9$ \\
\hline 2 & Moderate & $7-9.9$ \\
\hline 3 & Severe & $4-6.9$ \\
\hline 4 & Very severe & $<4$ \\
\hline
\end{tabular}


Postpartum anaemia has been defined as haemoglobin of less than $10 \mathrm{gm} / \mathrm{dl}$ and serum ferritin less than $15 \mu \mathrm{g} / \mathrm{l}$, in 24-48 hours post-delivery. In developing countries like India, the prevalence of anaemia associated with pregnancy stands as high as $50-80 \%$ when compared with the developed countries. Anaemia in third trimesterFactors contributing to such a wide disparity in statistics accounts to low intake of essential nutrient, predominantly vegetarian diet, repeated pregnancies at short intervals and chronic blood loss due to infection such as malaria, hookworm infestation, young mothers, not taking iron folic acid supplement in pregnancy etc. The most common type of anaemia during pregnancy and puerpurium is dimorphic anaemia due to isolated or combined nutritional deficiency of iron, vitamin B12, and folic acid. ${ }^{3}$

Erythropoiesis requires adequate amount of iron, folic acid, vitamin B12, vitamin C, traces of zinc, amino acids and erythropoietin. In pregnancy, there is an increase in demand of iron. In typical singleton gestation, the maternal need for iron averages $1000 \mathrm{mg}$. of these, 300 $\mathrm{mg}$ is for the fetus and placenta, $500 \mathrm{mg}$ for maternal haemoglobin mass expansion and $200 \mathrm{mg}$ is shed normally through gut, urine, skin. ${ }^{4}$ The total demand of $1000 \mathrm{mg}$ exceeds the iron store of most women and results in iron deficiency anaemia unless iron supplementation is given.

In India, the national nutritional anaemia control programme (NNACP) was started in 1970 and is being implemented through primary health centres and sub centres. It recommended pregnant women to take one iron tablet per day for at least 100 days (each tablet containing $100 \mathrm{mg}$ of elemental iron and $500 \mathrm{mcg}$ of folic acid) after first trimester of pregnancy; a similar dose applies to lactating women. Despite the vigorous efforts of NNACP, iron deficiency anaemia (IDA) is still widely prevalent in pregnant and postpartum women. ${ }^{5}$

Management of postpartum iron deficiency anaemia (PPIDA) includes dietary modifications along with pharmacotherapy. Dietary modification involves increasing total calorie intake along with increase in iron rich food stuffs such as spinach, green leafy vegetables, cereals, pulses (especially sprouts pulses), and jiggery, which is a rich source of iron and is a part of normal diet in rural Indian population etc. Along with this intake of vitamin $\mathrm{C}$ is of prime importance in maintaining homeostasis of iron metabolism in the body, as vitamin $\mathrm{C}$ enhances the absorption of iron, so regular consumption of vitamin $\mathrm{C}$ rich products.

Apart from the above mentioned dietary modification, Iron therapy itself is a definitive treatment of iron deficiency anaemia. Oral iron is an effective, cheap and safe way to replace iron and is practiced in government policies for anaemia prevention and treatment. Generally iron is given as $180-200 \mathrm{mg}$ in elemental form in two to three divided doses in between meals along with vitamin C. ${ }^{6}$

The various iron salts available are ferrous sulfate, ferrous fumarate, ferrous ascorbate, ferrous gluconate, carbonyl iron etc. After oral therapy, $\mathrm{Hb}$ starts rising from third week but replenishment of iron stores may take up to three months. Iron salts have their side effects in the form of nausea, epigastric discomfort, constipation or diarrhoea leading to non-compliance in some cases. This intolerance to oral iron can limit its efficacy.

Parenteral iron therapy is indicated when there is no compliance or intolerance to oral iron, impaired iron absorption, chronic blood loss, and gastrointestinal disorders limiting the therapeutic effects of oral iron therapy. Parenteral iron therapy ensures good compliance, rapid correction of anaemia and replenishment of iron stores. Type-I complexes iron dextran, iron dextrin have high molecular weight and high stability leading to slow release of iron, but there use its limited by systemic reactions like hypotension, urticarial, dizziness and sometimes anaphylactic reactions. Type-II complexes like iron sucrose is safe, usually not associated with anaphylactic reaction, and has minimum side effects, thus does not require test dose administration. Type-III complexes like iron gluconate are unstable labile complexes with molecular weight of less than 5000 Dalton's. Because of their low stability, these show less binding to transport protein, with greater quantity of free iron being released in a short interval of time, causing tissue toxicity. These drugs need multiple doses and prolonged infusion time. ${ }^{7}$

Thus a need for newer, safer and preferable single dose therapy.

Iron sucrose (IS) was FDA approved in November of 2000. Iron sucrose is iron hydroxide sucrose complex in water. The molecular weight of iron sucrose is 34,000 60,000 Dalton's. Iron sucrose is administered by intravenous bolus injection over 5-10 minutes or as short infusion in $100 \mathrm{ml}$ of normal saline over 15-20 minutes. No test dose is required. A maximum daily bolus dose of $200 \mathrm{mg}$ can be given at a time, for not more than thrice a week. A general side effect includes metallic taste, nausea, dizziness and local irritation.

Ferric carboxy maltose (FCM) is a novel non-dextran containing Type-I complex designed to be administered in large doses by rapid (over 15 minutes) intravenous infusion. $^{7}$ Its design allows for controlled and fast delivery with minimal risk of acute toxicity and there is a much wider therapeutic window as compared to its other counterparts. Efficacy and safety of FCM has been proved in many clinical trials done so far in patients with varying etiologies of anaemia like, inflammatory bowel disease chronic kidney disease congestive heart failure, heavy uterine bleeding and PPIDA. ${ }^{8-18}$ FCM injection leads to $\mathrm{Hb}$ rise along with replenishment of iron stores in 
much shorter time. Also, there is better tolerability with low risk of anaphylaxis and other adverse effects. Pfenniger et al compared FCM with iron sucrose and found them equally efficacious in treatment of PPIDA. FCM group showed better compliance due to less number of doses and fewer injection site problems. In a retrospective study on pregnant women with IDA, Christoph et al concluded that FCM is well tolerated and safe in pregnant women. ${ }^{18,19}$ Thus FCM seems promising in the treatment of PPIDA; however, there is an indispensable need for data study in Indian population.

\section{METHODS}

This open label, interventional, prospective study was carried out in the department of obstetrics and gynecology, LLRM Medical College, Meerut, Uttar Pradesh, India and SVBP Hospital, Meerut, Uttar Pradesh, India from November 2014 to November 2015.

All postpartum patients (postnatal or post caesarean) within 10 days of delivery with $\mathrm{Hb} \geq 7$ and $<10$ gms with serum ferritin $<15 \mathrm{ng} / \mathrm{dl}$ (at 38 weeks of gestation) were included in the study (excluding women with active liver diseases, women with hypo or hypertension). Other causes of anemia including worm infestation were excluded. Details history including dietary luster source of water supply, any no hair loss, chronic illness was taken followed by complete examination and investigations including general blood picture, RBC indices complete hemoglobin and liver function tests. Subjects were randomized and divided into 2 groupseach of 100 subjects:

- Group 1- Received $500 \mathrm{mg}$ of intravenous Iron sucrose divided in three doses of $200 \mathrm{mg}, 200 \mathrm{mg}$ and $100 \mathrm{mg}$ on alternate days $+500 \mathrm{gm}$ folic acid daily.

- Group 2- Received $500 \mathrm{mg}$ of intravenous Ferric Carboxymaltose (Ferium, Emcure Pharmaceuticals Ltd.) in a single dose +500 gm folic acid daily.

\section{RESULTS}

Table 2: Haematological parameters before therapy in two groups.

\begin{tabular}{|llll|}
\hline Parameters & $\begin{array}{l}\text { Group 1 } \\
\text { Mean } \pm \text { SD }\end{array}$ & $\begin{array}{l}\text { Group 2 } \\
\text { Mean } \pm \text { SD }\end{array}$ & $\begin{array}{l}\text { P } \\
\text { value }\end{array}$ \\
\hline $\mathrm{Hb} \%(\mathrm{gm} / \mathrm{dl})$ & $0.022 \pm 0.581$ & $8.037 \pm 0.629$ & .861 \\
\hline $\mathrm{MCV}$ & $76.68 \pm 5.86$ & $75.97 \pm 6.34$ & .415 \\
\hline $\mathrm{PCV}$ & $24.44 \pm 1.85$ & $24.66 \pm 2.2$ & .44 \\
\hline RBC Counts & $3.18 \pm .28$ & $3.24 \pm .271$ & .114 \\
\hline $\begin{array}{l}\text { Serum ferritin } \\
\text { (ng/ml) }\end{array}$ & $14.29 \pm 8.8$ & $14.31 \pm 5.51$ & .984 \\
\hline
\end{tabular}

The RBC count was $3.18 \pm .28$ in group 1 which increased to $3.77 \pm .271$ after treatment and in group 2 in increases from $3.24 \pm .271$ to $3.78 \pm .263$.
Table 3: Haematological parameters after therapy in both groups.

\begin{tabular}{|llll|}
\hline Parameters & $\begin{array}{l}\text { Group 1 } \\
\text { M=100 } \\
\text { Mean } \pm \text { SD }\end{array}$ & $\begin{array}{l}\text { Group 2 } \\
\text { Me100 } \\
\text { Mean } \pm \text { SD }\end{array}$ & $\begin{array}{l}\text { P } \\
\text { value }\end{array}$ \\
\hline $\mathrm{Hb} \%(\mathrm{gm} / \mathrm{dl})$ & $9.78 \pm .604$ & $10.12 \pm .623$ & $<.001$ \\
\hline $\mathrm{MCV}(\mathrm{H})$ & $80.08 \pm 6.05$ & $82.5 \pm 5.62$ & $<0.004$ \\
\hline $\mathrm{PCV}(\%)$ & $30.04 \pm 2.15$ & $31.23 \pm 2.10$ & $<.001$ \\
\hline $\begin{array}{l}\text { RBC Counts } \\
\text { (millions/cumm) }\end{array}$ & $3.77 \pm .271$ & $3.78 \pm .263$ & 0.812 \\
\hline $\begin{array}{l}\text { Serum ferritin } \\
\text { (ng/ml) }\end{array}$ & $62.17 \pm 22.86$ & $81.91 \pm 22.86$ & $<.001$ \\
\hline
\end{tabular}

All the haematological parameters were significantly better in group 2 on post treatment evaluation when compared to group 1 . The difference was highly significant ( $\mathrm{p}$ value <.001) for haemoglobin level, mean corpuscular volume, packed cell volume and serum ferritin.

The change from baseline was highly significant in group 2 ( $\mathrm{p}$ value <.001) except for RBC count. Mean use in $\mathrm{Hb}$ was $1.776 \mathrm{gm} / \mathrm{dl}$ for iron sucrose versus $2.086 \mathrm{gm} / \mathrm{dl}$ for ferric carboxymaltose which was significant ( $\mathrm{p}$ value $<.001$ ). Notably, serum ferritin which is a maker of iron stores rose significantly in group 2 as compared to group 1 ( $\mathrm{p}$ value <.001).

Table 4: Percentage of subjects achieving outcome.

\begin{tabular}{|c|c|c|c|}
\hline Parameters & $\begin{array}{l}\text { Group } 1 \\
\text { (Iron } \\
\text { sucrose) }\end{array}$ & $\begin{array}{l}\text { Group } 2 \\
\text { (Ferric Carbo- } \\
\text { xy maltose ) }\end{array}$ & $\begin{array}{l}P \\
\text { value }\end{array}$ \\
\hline $\begin{array}{l}\mathrm{Hb}>11 \mathrm{gm} / \mathrm{dl} \\
21 \text { at days }\end{array}$ & $2 \%$ & $12 \%$ & $<.001$ \\
\hline $\begin{array}{l}\text { Rise of } \geq 2 \\
\mathrm{gm} / \mathrm{dl} \text { at } 21 \\
\text { days }\end{array}$ & $24 \%$ & $88 \%$ & $<.001$ \\
\hline
\end{tabular}

Subjects in group 1 had significantly higher incidence of Nausea (10\% versus $5 \%$ ) vomiting (5\% versus $0 \%$ ), Burning at injection site (7\% versus $1 \%$ ) constipation (7\% versus $3 \%$ ) dizziness (7\% versus $6 \%$ ) fever $(5 \%$ versus $0 \%$ ) muscle cramps (6\% versus $0 \%)$ and tingling in limb (4\% versus $0 \%$ ) than group 2 .

\section{DISCUSSION}

Nutritional anemia in pregnancy and postpartum period is a public health problem especially in developing countries and commonest in iron deficiency anemia. Anemia in pregnancy and in postpartum period is significantly associated with both fetal and maternal morbidity.

Our study indicates that postpartum anemia can be treated effectively by ferric carboxymaltose as compared to iron sucrose with additional advantage of single dose regime and lower incidence of side effects. 
In our study, majority of cases were of low socioeconomic status, illiterate younger than 30 years of age, consuming diet deficient in calories and proteins.

In developing counties like India, early age of marriage and childbearing is more prevalent in rural areas becomes of ignorance towards female education as compared to urban area people low socioeconomic status causes poor maternal health became of illiteracy, customs and beliefs, place of women in society value of male children, poor nutrition, look of personal hygiene etc.

In our study total 200 post-partum women were given 300 injection of iron sucrose and 100 injections of ferric carboxymaltose. Both groups were given folic acid tablets and deworming therapy, baseline investigations done, follow up was done at 14 and 21 days and $\mathrm{Hb}$ and baseline investigation repeated.
Most of the studies regarding use of FCM and iron sucrose in PPIDA carried out in western population. Breymann et al their trial, reported mean age 27.7 years and most of study population belonged to middle and high socioeconomic status in our study, both groups were matching in all haematological parameters at the time of recruitment.

Van Wyck et al compared Hb improvement 2, 4, 6 weeks of therapy in parents al versus oral iron group. They found that more subject in parenteral group believed rise $>2 \mathrm{gm} / \mathrm{dl}$ and $<3 \mathrm{gm} / \mathrm{dl}$ and $\mathrm{Hb}>12 \mathrm{gm}$. Than oral group at 2 and 4 weeks. However at the end of 6 weeks, they seen no significant different between groups for $\mathrm{Hb}$ rise. This was unbilled, our study in which significantly more number of subjects had their $\mathrm{Hb}$ rise was $>2 \mathrm{gm}$, they also found that the median time to achieve $\mathrm{Hb}$ rise $<2$ $\mathrm{gm} / \mathrm{dl}$ was shorter in parenteral group as compared to oral iron group (7.0 versus 14.0 days) $\mathrm{p}$ value $<.001 .15$

Table 5: Comparison of various studies.

\begin{tabular}{|ll|ll|}
\hline Study & Type & Hb (gm/dl) $F C M$ versus Oral & Ferritin ng/ml \\
\hline Wyck V et al & RCT & 9.0 versus 9.0 & 26.1 versus 23.7 \\
\hline Bayman et al & RCT & 9.7 versus 9.7 & 45.5 versus 33.4 \\
\hline Sied et al & RCT & 8.9 versus 8.9 & 27.1 versus 23.9 \\
\hline Bhandal et al & RCT & 2.5 versus 7.3 & 11.0 versus 13.0 \\
\hline Verma $S$ et al & RCT & 7.58 versus 7.42 & - \\
\hline Present study & RCT & 8.02 versus 8.03 & 14.29 versus 14.31 \\
\hline
\end{tabular}

Similarly higher efficacy of FCM was reported by Seid et al when compared to oral iron. They compared $\mathrm{Hb}$ values between parenteral and oral iron at 1,2, 4 and 6 weeks of therapy. They also found that percentage of subjects achieving $\mathrm{Hb}>12 \mathrm{gm} / \mathrm{dl}$ was significantly greater in parenteral grop than oral group at 2, 4 and 6 weeks. (p $<.0001)$. Also, $91.4 \%$ subjects of parenteral group achieved $\mathrm{Hb}$ rise $>3 \mathrm{gm} / \mathrm{dl}$ compared with $64.6 \%$ in oral group in 6 weeks $(\mathrm{p}<0.0001)$. Faster response was seen in FCM group as compared to oral iron as evidenced by median time to achieve $\mathrm{Hb}>12 \mathrm{gm} / \mathrm{dl}$ (14 versus 27 days $\mathrm{p}=.0002$. Also importantly, difference in efficacy between FCM and oral iron was greater on subjects with most severe anemia. ${ }^{17}$

Verma S et al compared efficacy of injection iron sucrose at 7, 15 and 30 days. They found that mean rise of $\mathrm{Hb}$ was significantly higher in intravenous iron sucrose group in 7 days. $^{20}$

Similarly in other study by N Bhandal et al compared rise in $\mathrm{Hb}$ level and $\mathrm{S}$. ferritin level in iron sucrose versus oral iron at day 5, 14 and 40 after the start of treatment. Mean rise of $\mathrm{Hb}$ level from baseline at days 5 was $2.5 \mathrm{gm} / \mathrm{dl}$ in IS group and $0.7 \mathrm{gm} / \mathrm{dl}$ in oral iron group. Significant increase in S. ferritin levels on IS group by day 5 $(\mathrm{p}<.0001)$. In comparisons, no increase in ferritin levels was seen with oral iron supplementation. ${ }^{21}$

In our study serum ferritin which indicate iron status of body, increased significantly in FCM group than IS group, $67.6 \%$ versus 47.88 ( $\mathrm{p}$ value $<.001$ ) serum ferritin rise in iron sucrose group from 14.29 to $81.91 \mathrm{mg} / \mathrm{dl}$ which is significant. This replenishment of iron stores by FCM will prevent the recurrence of IDA.

In our study, no serious side effects were observed in either group. Overall incidence of side effects was found lower in FCM group than iron sucrose group. In our study, most common side effect in iron sucrose group was nausea $(10 \%)$ followed by burning at infection site, constipation and dizziness $(7 \%)$ then muscle cramps $(6 \%)$ but difference between groups was not significant.

Most common side effect in FCM group was headache $(8 \%)$ followed by dizziness the nausea, hypertension $(5 \%)$. These were no incidence of hypersensitive reaction in either group. Mild and transient derangements of liver enzymes observed in four subjects of FCM group and none is iron sucrose group. 
Seid et al reported lower incidence of adverse effects in parenteral group than oral group, no serious reactions in either group. Most common adverse effect in parenteral group was urticarial and in oral group was constipation. ${ }^{17}$

Wyck V et al reported higher incidence of skin problems like purities and rashes with parentral iron although very mild and transient in nature and subsided within 5-15 min. $37.5 \%$ of these subjects in FCM group experienced recurrent purities and rashes on receiving $2^{\text {nd }}$ dose but mild and transient. No episode of phlebitis in parentral group. ${ }^{15}$

\section{CONCLUSIONS}

The result of this study indicate that FCM causes significantly higher rise in $\mathrm{Hb}$ level as compared to parentral iron sucrose Notably, serum ferritin which a marker of iron stores increased significantly in FCM group versus iron sucrose group which prevents recurrence of iron deficiency anemia.

Side effects were minor and comparable both groups. FCM has an additional advantage of single dose administration as compared to multiple doses required in iron sucrose administration.

\section{Funding: No funding sources}

Conflict of interest: None declared

Ethical approval: The study was approved by the Institutional Ethics Committee

\section{REFERENCES}

1. Indian council of medical research evaluation of nutritional anaemia prophylaxis programm task force study New Delhi; 1989.

2. Center for disease control (CDC), criteria for anaemia in children and child bearing age women MMWR. 1989;38:400-4

3. Dutta DC. Medical and surgical illness complicating pregnancy. In Konar $\mathrm{H}$, editor. Text book of obstetrics, $7^{\text {th }}$ ed. London, new cenral agency $(\mathrm{P})$ Ltd; 2010:260-261.

4. Cunninghum FG, Lenevo KJ, Bloom SL, Hauth JC, Rouse DJ, Spong CY, Haematological disorder. Editor. Williams obstetrics, $23^{\text {rd }}$ edition. Philadelphia, McGraw Hil; 2010:1080.

5. Policy on control of nutritional anemia. Ministry of health and Family Walfare, Government of India. Available from; http;//hetv.org/pdf/anaemiapolicy.pdf. Accessed 1991.

6. Gupta U. Iron deficiency anemia of pregnancy. In: Trivedi SS, Puri M, Editors. Anemia in pregnancy, $1^{\text {st }}$ edition. New Delhi. jaypee; 2008:45-66.

7. Breymann C. Treatment of iron deficiency anemia in pregnancy and postpartum. In: Studd J, Tan SL, Chervenak FA, Editors. Current Progress in Obstetrics and Gynaecology, $1^{\text {st }}$ ed. Mumbai: Tree Life Media; 2012:135-148.
8. Kulnigg S, Stoinov S, Simanenkov V, Dudar LV, Karnefal W, Garcia LC, et al. A novel intravenous iron formulation for treatment of anaemia in inflammatory bowel disease: the ferric carboxy maltose (Ferinject) Randomized Conrlled Trial. Am J Gastroenterol. 2008;103(5):1182-92.

9. Evstatiev R, Marteau P, Iqbal T, Khaliff IL, Stein J, Bokemeyer B, et al. Fergi study group. Fergicor; a randomized controlled trial on ferric carboxy maltose for iron deficiency anaemia in inflammatory diseases. Gastroenterology. 2011;141(3):846-53.

10. Grimelt AC, Cohen CD, Fehr T, Serra AL, Wuetrich RP. Safety and tolerability of ferric carboxy maltose (FCM) for treatment of iron deficiency in patient with chronic kidney disease and kidney transplant recipient. Clin Nephrol. 2009;71(2):125-9.

11. Covic A, Mircescu G, The safety and efficacy of intravenous ferric carboxymaltose in anaemic patients undergoing hemodialysis: a multicentre, open label, clinical study. Nephrol Dial Transplant. 2010;25(8):2722-30.

12. Quinibi WY, Martinez C, Smith M, Benjamin J, Mangione A, Roger SD. A randomized controlled trial comparing intravenous ferric carboxy maltose with oral iron for treatment of iron deficiency anaemia of non-dialysis dependent chronic kidney disease patients. Nephrol Dial Transplant. 2011;26(5):1599-607.

13. Anker SD, Colet JC, Filippatos G, Willenheimer R, Dickstein K, Drexler $\mathrm{H}$, et al. Fair-HF Trial investigators. Ferric carboxymaltose in patients with heart failure and iron deficiency. $\mathrm{N}$ Engl J Med. 2009;361(25):2436-48.

14. Wyck DBV, Mangione A, Morrison J, Hadley PE, Jehle JA, Goodnough LT. Large-dose intravenous ferric carboxymaltose injection for iron deficiency anaemia in heavy uterine bleeding: a randomized, controlled trial. Transfusion. 2009;(12):2719-28.

15. Wyck DBV, Martens MG, Seid MH, Baker JB, Mangione A. Intravenous ferric carboxymaltose compared with oral iron in the treatment of postpartum anaemia: randomized controlled trial. Obstet Gynecol. 2007;110:267-78.

16. Breymann C, Gliga F, BejenariuC, Strizhova N. Comparative efficacy and safety of intravenous ferric carboxymaltose in the treatment of postpartum iron deficiency anaemia. Int $\mathbf{J}$ Gynaecol Obstet. 2008;(1):67-73.

17. Seid MH, Derman RJ, Baker JB, Banach W, Goldberg C, Rogers R. Ferric carboxymaltose injection in the treatment of postpartum iron deficiency anaemia: a randomized controlled clinical trial. Am J Obstet Gynecol. 2008;199(4):435:1-7.

18. Pfenniger A, Schuller C, Cristoph P, Surbech D. afety and efficacy of high dose intravenous iron carboxymaltose versus iron sucrose for treatment of postpartum anaemia. J Perinat Med. 2012;40(4):397-402.

19. Christoph P, Schuller C, Studer H, Irion O, De Tejada BM, Surbek D. Intravenous iron treatment in 
pregnancy: comparison of high-dose ferric carboxymaltose versus iron sucrose. J Perinat Med. 2012;40(5):469-74.

20. Verma S, Inamdar SA, Malhoea N. Intravenous vessus oral iron in postpartum patients in rural Ace
Jow nal of South Asian federation of oblates and Gynecology May-august; 2011.

21. Bhendal $\mathrm{N}$ Russell $\mathrm{R}$, Intervenes versus oral from therapy for PPA. BJOG. 2006;113:124-5.

Cite this article as: Singh S, Dhama V,

Chaudhary R, Singh P. Comparing the safety and efficacy of intravenous iron sucrose and intravenous ferric carboxymaltose in treating postpartum anemia. Int J Reprod Contracept Obstet Gynecol 2016;5:1451-6. 